\title{
Alternative Econometric Methods for Information-based Equity-selling Mechanisms
}

\author{
Lee Cheng-Few and YiLin $\mathrm{Wu}$
}

${ }^{a}$ Department of Finance and Economics, School of Business, Rutgers University, Piscataway, New Jersey, 08854-8054, USA, Tel: 732-4453907, Fax: 732-4455927, E-mail: lee@rbs.rutgers.edu

${ }^{b}$ Department of Quantitative Finance, College of Technology Management, National Tsing Hua University, Hsinchu, Taiwan 30013, R.O.C., Tel:886- 035742225, Fax: 886-035742225, E-mail: yilinwu@mx.nthu.edu.tw

\begin{abstract}
Extant research offers mixed empirical results on the information content of private placements. Hertzel and Smith (1993) suggest that, on average, private placement firms are undervalued. On the other hand, Hertzel, Lemmon, Linck, and Rees (2002) show that private placement firms experience significant negative long-run post-announcement stock price performance and that high levels of capital expenditures around private placement reflect managerial overoptimism. Empirical work examining the information content of private placements typically takes the approach based on proxies for information asymmetry that suffers the intrinsic errors-in-variables problem. This paper circumvents the empirical difficulty by developing the two-stage estimation approach and the conditional correlation approach. The conditional correlation coefficient varies between -1 and +1 that allows comparisons across samples feasible. Thus, it prevails over the two-stage estimation approach to identify the significance of the information content of equity-selling mechanisms.
\end{abstract}

\footnotetext{
${ }^{0}$ Corresponding author contact information: Department of Quantitative Finance, College of Technology Management, National Tsing Hua University. E-mail: yilinwu@mx.nthu.edu.tw
} 


\section{Introduction}

One important connection between asymmetric information and undervaluation in the area of corporate finance is the choice of equity-selling mechanisms. The fundamental implication of asymmetric information on the choice of equity-selling mechanisms is that firms issuing private (public) offerings will be on average undervalued (overvalued) (Myers and Majluf (1984), Hertzel and Smith (1993)). If firms are undervalued such that issuing equity to the public investors will dilute value of the existing shareholders, then firms may choose not to issue equity publicly and instead resort to the private placement market so as to convey their favorable private information to sophisticated (accredited) investors in the negotiation process. In this framework, the decision to go to the private placement market conveys that the firms are undervalued. On the other hand, the extant behavioral finance literature suggests that private placements reflect managers' overconfidence on the future firm prospects (Hertzel, Lemmon, Linck, and Rees (2002)) or that private placement firms correctly anticipate naive investors' misvaluation and take advantage of the capital market conditions (Huson, Malatesta, and Parrino (2006)).

The empirical evidence on the information content of private placements is conflicting. Some studies find significant positive short-term stock price reaction to private placement announcements (Wruck (1989), Hertzel and Smith (1993)) and favorable ex-post outcomes (Hertzel and Rees (1998), Goh, Gombola, Lee, and Liu (1999)), unlike public offerings (Masulis and Korwar (1986), Jain (1992)). Others find that, similar to public offering firms, private placement firms experience significant negative long-run post-announcement stock price performance (Krishnamurthy, Spindt, Subramaniam and Woidtke (2005), Hertzel, Lemmon, Linck, and Rees (2002)) and that high levels of capital expenditures around private placement reflect managerial overoptimism (Hertzel, Lemmon, Linck, and Rees (2002)).

Empirical work examining the information content of private placements typically takes the approach based on proxies for information asymmetry ( $\mathrm{Wu}(2004))$. The primary difficulty with the proxies is the errors-in-variables problem. Because information asymmetry is unobservable, any empirical attempt to capture information asymmetry requires the use of proxies. It is plausible that some proxies capture underlying intrinsic characteristics rather than information asymmetry. As a result, an inference drawn from the significance of the coefficients of the proxies for information asymmetry may be biased.

To circumvent the potential biases embedded in the approach based on surrogates, this paper distinguishes observable and unobservable variables. This distinction is important as will be shown later that we cannot ignore the private information simply because the surrogates and private information are highly related neither can we ignore the unobservable variables when the surrogates are empirically irreverent. Furthermore, this paper uses two empirical strategies in the research de-

sign. First, this paper uses insider trading prior to the announcement of equity-selling mechanisms 
to measure the other insiders' decision. This is because most studies indicate significant changes in insider trading patterns before equity-offering announcement (Karpoff and Lee (1991), Kahle (2000), Clarke, Dunbar, and Kahle (2001), Lee (1997)) and researchers have concluded that insider trades reveal important non-public information (John and Mishra (1990), Damodaran and Liu (1993), Seyhun (1986), Meulbroek (1992)). Second, this paper uses both the two-stage estimation approach and the conditional correlation approach. Specifically, this paper assumes that the same set of private information explains both insider trading activity and the choice of equity-selling mechanisms. The two-stage estimation approach uses the estimated residuals of insider purchase regression and insider sale regression (hereafter referred to as abnormal insider purchases and abnormal insider sales, respectively) to measure private information. Assuming that both insider trading activity and the equity-selling mechanisms choice are driven by the same set of private information, the two-stage estimation approach hypothesizes that if abnormal insider purchases correlate positively, negatively, or are uncorrelated with the probability of making private placements, then the private placement firms are undervalued, overvalued, or evenly valued, respectively. An opposite prediction holds for the information content of abnormal insider sales. In addition to the two-stage estimation approach, this paper uses the conditional correlation approach to investigate the information content of the equity-selling mechanism choice. Expressing equity-selling mechanism choice and insider purchases (or insider sales) as a pair of conditional equations, whereby the conditioning variables measure the public information, as long as the unobservable variables are correlated, the generalized residuals (or standardized residuals) will be correlated. Consequently, the conditional correlation approach hypothesizes that if the generalized residuals of the pair of conditional equations correlate positively, negatively, or are uncorrelated, then this statistical relationship serves as evidence that private placements signal positive, negative, or no firm-specific private information, respectively. Compared with the two-stage estimation approach that is based on the unconstrained coefficient of the abnormal insider purchases (abnormal insider sales), the conditional correlation coefficient varies from - 1 to +1 . Consequently, it offers the additional advantage that allows across samples comparisons both the direction and magnitude of private information revealed in the equity-selling mechanism choices. In addition, this paper introduces non-parametric approaches when the data are sensitive to the arbitrary imposition of linear functional form and normal distribution of the error disturbances.

This paper is organized as follows. Section 2 describes and develops hypothesis about the informational content of equity-selling mechanisms. Section 3 derives the econometric estimation methodology. Section 4 concludes the paper. 


\section{The information contents of equity-selling mechanisms}

This section explores the information contents of equity-selling mechanisms. First, the information content is that private placement firms may be undervalued. Hertzel and Smith (1993) extend Myers and Majluf (1984) to the case of private placements. In Hertzel and Smith (1993), managers with favorable information who, under the Myers and Majluf assumptions, would choose not to issue equity publicly and thereby forego a profitable investment opportunity may resort to the private placement market so as to convey their favorable information to investors in the negotiation process. Furthermore, there is a difference in investor sophistication between private placement market and public offering market. The undervalued firms avoid the underinvestment problem by placing equity with sophisticated (accredited) investors who are able to assess true firm value. In equilibrium, firms that view themselves as undervalued choose private placements.

Secondly, the private placements may reflect managers' overconfidence on the future firm prospects. This is consistent with the documented negative long-term post placement stock price performance (Krishnamurthy et al. (2005), Hertzel et al. (2002)) and that high levels of capital expenditures around private placement reflects managerial overoptimism (Hertzel et al. (2002)).

Lastly, the private placements may reflect managers' anticipation on naive investors' overreaction and take advantage of it. Unlike public offerings that have negative abnormal returns for both the short-term and the long-term (Loughran and Ritter (1995), Loughran and Ritter (1997)), private placements have significant positive stock price reaction to announcement but are followed by negative long- term (three to five years) post-issue stock price performance. Behavioral finance attributes long-term return continuation (reversal) in public (private) offerings to underreaction (overreaction) to information conveyed in announcements. Naive investors incorrectly expect that the superior pre-public offering performance will continue and the poor pre-private offering performance will improve. Huson, Malatesta, and Parrino (2006) show that private placements are more likely to occur following periods of superior capital market conditions. Furthermore, private placement offer prices are not efficient with respect to public information as measured discounts are related to capital market conditions. In summary, private placement firms correctly judge naive investors' misvaluation and take advantage of the capital market conditions.

The above three information contents of equity-selling mechanisms differ in that the first reveals managers' superior knowledge about future firm cash flow, the second reveals management hubris about the future cash flow, while the last reveals managers' correct anticipation of the market misvaluation.

Here, we use insider trading prior to the equity-selling mechanisms to measure the other contemporaneous informed parties' decision. Inferring the roles of equity-selling mechanisms from the ex post consequences (e.g., long-term stock price performances and accounting performances) would not be a powerful test, since the firms' qualities may have evolved directly due to the equity-selling 
mechanisms (Wruck (1989). There are several major reasons to expect that insider trading reflects insiders' superior knowledge about a firm's prospects, insiders' personal belief about their firms' prospects, or insiders' exploitation of market misvaluation: (1) studies on insider trading activity conclude that insiders trade profitably and the power of using insider trading patterns to predict stock returns ranks above other potential trading strategies (Lakonishok and Lee (2001), Seyhun (1992), (2) Boehmer and Netter (1997) use insider trading as a proxy for insiders' personal belief about their firms' prospects to investigate managements' resistance on acquisitions and takeovers. Abnormal insider purchases prior to private placements may reflect insider overoptimism about the future prospects of the firm, (3) Rozeff and Zaman (1998) suggest that insider purchases (sales) are positively (negatively) related to book-to-market ratio which measures security misevaluation, (4) Piotroski and Roulstone (2005) document that insider trades reflect both personal belief and superior knowledge about future cash flow realization., and (5) the private information set leading to insider trading is comprehensive. Therefore, it is unlikely that insider trades and equity-selling mechanisms are driven by different sets of private information. Most studies examining the timing of insider trades indicate significant changes in insider trading patterns before the announcements of various corporate events, including equity offerings (Kahle (2000)), earning announcements (Park, Jang, and Loeb (1995)), dividend announcements (John and Lang (1991)), capital expenditure announcements (John and Mishra (1990)), and merger announcements (Keown and Pinkerton (1981)).

For these reasons, this paper hypothesizes that the likelihood of placing equity privately is expected to correlate positively with the likelihood of insider purchases and negatively with the likelihood of insider sales.

\section{Alternative econometric methods for information-based equity- selling mechanisms}

Empirical work examining the information contents of equity-selling mechanisms is typically based on proxies for information asymmetry $(\mathrm{Wu}(2004)$. The primary difficulty with the proxies is the errors-in-variables problem. Because information asymmetry is unobservable, any empirical attempt to capture information asymmetry requires the use of proxies. It is plausible that some proxies capture underlying intrinsic characteristics rather than information asymmetry. As a result, an inference drawn from the significance of the coefficients of the proxies for information asymmetry may be biased.

To circumvent the potential biases embedded in this approach, this paper distinguishes observable and unobservable variables. This distinction is fundamental for understanding the parameters of interest and the inferences based on them. This paper assumes that the firm-specific information set $x$ has two components such that $x=\left(x_{o b s}, x_{u n o b s}\right)$, where $x_{o b s}$ and $x_{u n o b s}$ denoting the vectors 
of exhaustive set of firm-specific variables observed by public investors and insiders, respectively. To control for the surrogates for the private information, $x_{o b s}$ include the firm's age at IPO dates, the duration between IPO dates and equity offering announcements in terms of years, the bid-ask spread, the number of shareholders, and monthly trading volume/the average of shares outstanding over the previous two years. To control for the impact of security misvaluation (Rozeff and Zaman (1998), Piotroski and Roulstone (2005)), $x_{o b s}$ include contemporaneous 1-month buy-and-hold equal-weighted market-adjusted return and the firm's book-to-market ratio. $x_{o b s}$ also include variables to capture pre-issue ownership structure and the extent of CEOs organization power (Wruck (1989), Wu (2004), Barclay, Holderness, and Sheehan (2007)), prior financial performance and financial constraints, firm size, issue size, firm risk, the impact of the stock options (Biais and Hillion (1994)), the stock exchanges (Lin and Howe (1990)), and the identities of insiders (Seyhun (1986)). ${ }^{1}$ Let $\left(c_{i}^{*}, p_{i}^{*}\right)$ denote a pair of informed parties' decisions. While $\left(c_{i}^{*}, p_{i}^{*}\right)$ are unobserved, the underlying decision outcome, that is, intensive insider purchases (sales) and the equity selling mechanisms are observed. $\left(c_{i}, p_{i}\right)$ are related to $\left(c_{i}^{*}, p_{i}^{*}\right)$ in the sense that $c_{i} \equiv I_{(0, \infty)}\left(c_{i}^{*}\right)$ and $p_{i} \equiv I_{(0, \infty)}\left(p_{i}^{*}\right)$ or $p_{i}^{*}$ depending on the econometric specifications. Specifically, $c_{i}$ equals one or zero, depending on whether the firms choose private or public offerings and $p_{i}$ measures an intensive insider purchases (sales) event. We use two standard measures of an intensive insider purchase (sale) event. First, three or more insider purchases (sales) and no insider trade occurring in the opposite direction in the prior 1, 3, 6, or 12 months of the equity offering announcement (Jaffe (1974), Rozeff and Zaman (1988), Lin and Howe (1990)). Second, a positive (negative) difference between insider purchases and sales in the prior 1, 3, 6, or 12 months of the equity offering announcement (John and Lang (1991)).

We introduce two benchmark estimation approaches, including the two-stage estimation approach and the conditional correlation approach. Both approaches are performed under three alternative econometric specifications, including: (1) two independent probit models (single-equation model), (2) the bivariate probit methods where $p_{i}$ is a binary variable that equals one if three or more insider purchases (sales) and zero insider sales (purchases) occur in the prior 1, 3, 6, or 12 months of the equity offering announcement and zero otherwise, and (3) the mixed binary and censored probit models where $p_{i}$ is a censored variable that equals the positive (negative) net insider purchases occur in the prior 1, 3, 6, or 12 months of the equity offering announcement and zero otherwise. Note that in all three econometric specifications $c_{i}=1$ if firm $i$ chooses private placements and $c_{i}=0$ if firm $i$ chooses public offerings. In addition, this paper introduces non-parametric approaches as a robustness check when the data are sensitive to the functional form and normal distribution of the error disturbances.

\footnotetext{
${ }^{1}$ See Lee and $\mathrm{Wu}(2007)$ for the detailed list of observable factors affecting insider trades and equity-selling mechanisms.
} 


\subsection{The two-stage estimation approach}

This subsection describes the two-stage estimation approach used to test the information contents of equity-selling mechanisms. Equity selling mechanisms and intensive insider purchases (sales) are denoted by $\left(c_{i}, p_{i}\right)$. Assume,

$$
\begin{aligned}
p_{i, t}^{*} & =x_{o b s, i, t}^{T} \gamma_{1}+x_{u n o b s, i, t}^{T} \gamma_{2}+\lambda_{t}+\widetilde{u_{i, t}}, \\
c_{i, t}^{*} & =x_{o b s, i, t}^{T} \beta_{1}+x_{u n o b s, i, t}^{T} \beta_{2}+\lambda_{t}+\widetilde{v_{i, t}}
\end{aligned}
$$

where $E\left(\widetilde{u_{i, t}} \mid x_{o b s, i, t}, x_{\text {unobs }, i, t}\right)=0, E\left(\widetilde{v_{i, t}} \mid x_{o b s, i, t}, x_{u n o b s, i, t}\right)=0$, the subscript $i$ indexes the firm, $t$ denotes time, $c_{i}$ equals one or zero depending on whether the firms choose private or public offerings, $p_{i}$ measures an intensive insider purchases (sales) event and the year dummies $\lambda$ captures the unobserved time-varying factor that is common across firms. Again, we assume that the firm-specific information $x$ has two components, $x_{o b s}$ and $x_{u n o b s}$, denoting the vectors of exhaustive set of firm-specific variables observed by public investors and insiders, respectively. $x_{o b s}$, includes measures for security misvaluation, information asymmetry, firm ownership structure, financial performances, etc. ${ }^{2}$ We assume that the conditional distribution of $x_{u n o b s, i}$ given $x_{o b s, i}$, depends on $x_{o b s, i}$ only through a linear regression function, i.e., a linear relationship exist between surrogates for the private information and private information

$$
x_{u n o b s, i, t}=A x_{o b s, i, t}+\widetilde{e_{i, t}},
$$

where $E\left(\widetilde{e_{i, t}} \mid x_{o b s, i, t}\right)=0$ and $\operatorname{Var}\left(\widetilde{e_{i, t}} \mid x_{o b s, i, t}\right)=\sum_{e}$.

As the public investors cannot directly observe $x_{u n o b s, i, t}$, equation (1) can be rewritten as

$$
\begin{aligned}
& p_{i, t}^{*}=x_{o b s, i, t}^{T}\left(\gamma_{1}+A^{T} \gamma_{2}\right)+\lambda_{t}+\widetilde{e_{i, t}} \gamma_{2}+\widetilde{u_{i, t}} \\
& c_{i, t}^{*}=x_{o b s, i, t}^{T}\left(\beta_{1}+A^{T} \beta_{2}\right)+\lambda_{t}+\widetilde{e_{i, t}} \beta_{2}+\widetilde{v_{i, t}}
\end{aligned}
$$

$\widetilde{e_{i, t}} \gamma_{2}+\widetilde{u_{i, t}}$ in equation (2) is called the residuals of intensive insider trading regression or abnormal insider trading. From the law of iterated expectation, $E\left(\widetilde{e_{i, t}}{ }^{T} \gamma_{2}+\widetilde{u_{i, t}} \mid x_{o b s, i, t}\right)=0$ and $E\left(\widetilde{e_{i, t}} T \beta_{2}+\widetilde{v_{i, t}} \mid x_{o b s, i, t}\right)=0$, given that $E\left(\widetilde{u_{i, t}} \mid x_{o b s, i, t}\right)=0$ and $E\left(\widetilde{v_{i}} \mid x_{o b s, i, t}\right)=0$.

Two-stage estimation leads to

\footnotetext{
${ }^{2}$ Throughout the paper, we assume that insiders' both decisions are related to the same $x_{o b s}$. The logic extends directly to more complicated models where each decision is related to an unique vector of observable variables, since we can partition $x_{o b s, i, t}$ into $\left(x_{o b s 1, i, t}, x_{o b s 2, i, t}\right)$, where$$
p_{i, t}=\left(x_{o b s 1, i, t}, x_{o b s 2, i, t}\right)\left(\begin{array}{c}
0 \\
\gamma_{1}
\end{array}\right)+x_{u n o b s, i, t}^{T} \gamma_{2}+\lambda_{t}+\widetilde{u_{i, t}},
$$$$
c_{i, t}=\left(x_{o b s 1, i, t}, x_{o b s 2, i, t}\right)\left(\begin{array}{c}
\beta_{1} \\
0
\end{array}\right)+x_{u n o b s, i, t}^{T} \beta_{2}+\lambda_{t}+\widetilde{v_{i, t}} \text {, }
$$ 


$$
c_{i, t}^{*}=\left(\widetilde{e_{i, t}} \gamma_{2}+\widetilde{u_{i, t}}\right) \beta_{3}+x_{o b s, i, t}^{T}\left(\beta_{1}+A^{T} \beta_{2}\right)+\lambda_{t}+\widetilde{w_{i, t}},
$$

with $\widetilde{w_{i, t}}=\widetilde{v_{i, t}}-\widetilde{u_{i, t}}$ and $E\left(\widetilde{w_{i, t}} \mid x_{o b s, i, t}\right)=0$, then $\beta_{3}=\frac{\beta_{2}}{\gamma_{2}}$

The estimated residuals of intensive insider purchase regression (i.e., abnormal insider purchases), ${\widetilde{e_{i, t}}}^{T} \gamma_{2}+\widetilde{u_{i, t}}$, measure unobserved private information. This is because $\beta_{3}$ is purged of firm-specific public information and transitory differences for firm $i$ across years. The signs of $\beta_{2}$ and $\gamma_{2}$ indicate the sign of $\beta_{3}$. Accordingly, if $\beta_{3}$ is significantly positive, negative, or is indifferent from zero, then the private placement signals positive, negative, or no firm-specific private information, respectively. An opposite interpretation holds for the estimated residuals of intensive insider sale regression (i.e., abnormal insider sales).

Compared with the framework using the proxy approach ( $\mathrm{Wu}(2004))$, an emphasis here is that the two-stage estimation approach distinguishes between public and private information. The interpretation of the information content of equity-selling mechanism choice is not based on the coefficients of the surrogates of private information but on the coefficient $\left(\beta_{3}\right)$ of the residuals of intensive insider trading regression. Since the inference of the information role is drawn from the significance of $\beta_{3}$, the regression (3) tells us that we cannot ignore the private information simply because the surrogates and private information are highly related ( $A$ is significant), neither can we ignore the unobservable variables when the surrogates are empirically irreverent $\left(\beta_{1}+A^{T} \beta_{2}\right.$ is insignificant).

\subsection{The conditional correlation approach}

In a purely statistical sense, for any two informed parties' decisions, as long as a pair of unobservable variables is correlated, conditional on the observable variables, the residuals of these two informed parties' decisions will be correlated. The conditional correlation coefficient is derived from the correlation between the generalized residuals (or the standardized residuals) of the intensive insider trading regression and the equity-selling mechanism choice regression.

$$
\begin{aligned}
& p_{i, t}^{*}=x_{o b s, i, t}^{T}\left(\gamma_{1}+A^{T} \gamma_{2}\right)+\lambda_{t}+\widetilde{e_{i, t}} \gamma_{2}+\widetilde{u_{i, t}} \\
& c_{i, t}^{*}=x_{o b s, i, t}^{T}\left(\beta_{1}+A^{T} \beta_{2}\right)+\lambda_{t}+{\widetilde{e_{i, t}}}^{T} \beta_{2}+\widetilde{v_{i, t}}
\end{aligned}
$$

The conditional correlation coefficient is given by

$$
\operatorname{Corr}\left(\widetilde{e_{i, t}} \gamma_{2}+\widetilde{u_{i, t}}, \widetilde{e_{i, t}} \beta_{2}+\widetilde{v_{i, t}} \mid x_{o b s, i, t}\right)
$$




$$
\begin{aligned}
& =\frac{\operatorname{Cov}\left(\widetilde{e_{i, t}} \gamma_{2}+\widetilde{u_{i, t}}, \widetilde{e_{i, t}}{ }^{T} \beta_{2}+\widetilde{v_{i, t}} \mid x_{o b s, i, t}\right)}{\sqrt{\operatorname{Var}\left(\widetilde{e_{i, t}^{T}} \gamma_{2}+\widetilde{u_{i, t}} \mid x_{o b s, i, t}\right)} \sqrt{\operatorname{Var}\left(\widetilde{e_{i, t}} \beta_{2}+\widetilde{v_{i, t}} \mid x_{o b s, i, t}\right)}} \\
& =\frac{\gamma_{2}^{T} \sum_{e} \beta_{2}}{\left(\gamma_{2}^{T} \sum_{e} \gamma_{2}+\sigma_{u}^{2}\right)^{1 / 2}\left(\beta_{2}^{T} \sum_{e} \beta_{2}+\sigma_{v}^{2}\right)^{1 / 2}} .
\end{aligned}
$$

The necessary and sufficient condition for $\operatorname{Corr}\left({\widetilde{e_{i, t}}}^{T} \gamma_{2}+\widetilde{u_{i, t}},{\widetilde{e_{i, t}}}^{T} \beta_{2}+\widetilde{v_{i, t}} \mid x_{o b s, i, t}\right)$ to be positive is $\gamma_{2}^{T} \sum_{e} \beta_{2}>0$. Two special cases can be summarized as follows:

- If $\operatorname{dim}\left(\sum_{e}\right)=p>1$, with $\sum_{e}=\operatorname{diag}\left\{\sigma_{e, 1}^{2}, \ldots, \sigma_{e, p}^{2}\right\}$ and $\beta_{2, j} \gamma_{2, j}>0$ for $j=1, \ldots, p$, then $\gamma_{2}^{T} \sum_{e} \beta_{2}>$ 0.

- If $\operatorname{dim}\left(\sum_{e}\right)=1, \gamma_{2}^{T} \sum_{e} \beta_{2}>0$ if and only if $\gamma_{2} \beta_{2}>0$.

The direction of the conditional correlation depends on the sign of the numerator, $\gamma_{2}^{T} \sum_{e} \beta_{2}$. In the case where the off-diagonal elements of $\sum_{e}$ are zero and each element of the two column vectors, $\beta_{2}$ and $\gamma_{2}$, is of the same sign (except for the zero vector), then $\gamma_{2}^{T} \sum_{e} \beta_{2}$ is greater than zero. If, instead of being multidimensional, $x_{u n o b s, i}$ can be fully captured in a variable, then $\beta_{2} \sigma_{e}^{2} \gamma_{2}$ is greater than zero if and only if $\gamma_{2} \beta_{2}$ is greater than zero.

Note that the conditional correlation coefficient that we explore is quite different from Pearson correlations. Conditioning on firm-specific public information and transitory differences for firm $i$ across years, the conditional correlation coefficient from equation (4) is purged of firm-specific public information and transitory differences for firm $i$ across years. Accordingly, if $\widetilde{e_{i, t}}{ }^{T} \gamma_{2}+\widetilde{u_{i, t}}$ correlates positively, negatively, or is uncorrelated with $\widetilde{e_{i, t}} \beta_{2}+\widetilde{v_{i, t}}$, then this statistical relationship serves as evidence that private placements signal positive, negative, or no firm-specific private information, respectively.

Comparing equations (2) and (4) shows that the sign of the coefficient $\left(\beta_{3}=\frac{\beta_{2}}{\gamma_{2}}\right)$ of the residuals of intensive insider trading regression is the same as that of conditional correlation coefficient. ${ }^{3}$ There are two major reasons that the conditional correlation approach may prevail over the two-stage estimation approach. First, the conditional correlation coefficient which is bounded by -1 and 1 permits across samples comparisons the magnitude of private information revealed in equity-selling mechanism choices, unlike the two-stage estimation approach that suffers the inherent incommensurate of coefficient of the residuals of intensive insider trading regression $\left.\left({\widetilde{e_{i, t}}}^{T} \gamma_{2}+\widetilde{u_{i, t}}\right)\right)$ among samples. Second, at each fitted probability, the variance of the residuals of intensive insider trading regression equals fitted probability times (1-fitted probability). Thus if fitted probability is high, the variance of the abnormal insider trading are either very small or large. As a result, the abnormal insider trading may have a skew distribution. .

\footnotetext{
${ }^{3}$ Here, we assume that the conditional correlation coefficient remains constant over time. This assumption reduces the number of parameters considerably and hence, makes efficient estimation possible. Note that we include year dummies $\lambda_{t}$ throughout the analysis to capture any unobserved time-varying factors that are common across firms.
} 
Both the two-stage estimation approach and the conditional correlation approach can be performed under the three variations of probit models including the two independent probit model, the bivariate probit model that explicitly accounts for cross equation impact, and the mixed binary and censored probit model where one response variable is continuous and the other is binary. For brevity, we consider the conditional correlation approach only. The derivation applies directly to the twostage estimation approach.

\subsubsection{Two independent probit models (single-equation model)}

We can reparameterize equation (2) as

$$
\begin{aligned}
& p_{i, t}^{*}=x_{o b s, i, t}^{T} \gamma+\lambda_{t}+\widetilde{\eta_{i, t}}, \\
& c_{i, t}^{*}=x_{o b s, i, t}^{T} \beta+\lambda_{t}+\widetilde{\varepsilon_{i, t}},
\end{aligned}
$$

with $\gamma=\gamma_{1}+A^{T} \gamma_{2}, \widetilde{\eta_{i, t}}=\widetilde{e_{i, t}} \gamma_{2}+\widetilde{u_{i, t}}, \beta=\beta_{1}+A^{T} \beta_{2}$, and $\widetilde{\varepsilon_{i, t}}=\widetilde{e_{i, t}}{ }^{T} \beta_{2}+\widetilde{v_{i, t}}$.

As $p_{i} \equiv I_{(0, \infty)}\left(p_{i}^{*}\right)$ and $c_{i} \equiv I_{(0, \infty)}\left(c_{i}^{*}\right)$, then

$$
p\left(p_{i, t}=1\right)=p\left(p_{i, t}^{*}>0\right)=I *\left(x_{o b s, i, t}^{T} \gamma+\lambda_{t}+\widetilde{\eta_{i, t}}>0\right)=p\left(-\widetilde{\eta_{i, t}}<x_{o b s, i, t}^{T} \gamma+\lambda_{t}\right)=
$$

$\Phi\left(x_{o b s, i}^{T} \gamma+\lambda_{t}\right)$

$$
p\left(c_{i, t}=1\right)=p\left(c_{i, t}^{*}>0\right)=I *\left(x_{o b s, i, t}^{T} \beta+\lambda_{t}+\widetilde{\varepsilon_{i, t}}>0\right)=p\left(-\widetilde{\varepsilon_{i, t}}<x_{o b s, i, t}^{T} \beta+\lambda_{t}\right)=
$$
$\Phi\left(x_{o b s, i, t}^{T} \beta+\lambda_{t}\right)$,

Let $\Phi$ denote the cumulative distribution function of $N(0,1)$ with $\left(\begin{array}{c}\widetilde{\eta_{i, t}} \\ \widetilde{\varepsilon_{i, t}}\end{array}\right) \stackrel{\text { i.i.d }}{\sim} N\left(0, I_{2}\right)$, where $I_{2}$ is the identity matrix of order two. ${ }^{4}$

The single-equation model computes the generalized residuals, $\widehat{\eta}_{i}$ and $\widehat{\varepsilon_{i}}$, given by the conditional means, $\widehat{E}\left(\widehat{\eta}_{i} \mid p_{i}\right)$ and $\widehat{E}\left(\widehat{\varepsilon_{i}} \mid c_{i}\right)$, respectively. For example, $\widehat{\varepsilon_{i}}=\widehat{E}\left(\widehat{\varepsilon_{i}} \mid c_{i}=1\right)=\frac{\phi\left(x_{o b s, i, t}^{T} \beta+\lambda_{t}\right)}{\Phi\left(x_{o b s, i, t}^{T} \beta+\lambda_{t}\right)}$ or $\widehat{\varepsilon_{i}}=\widehat{E}\left(\widehat{\varepsilon_{i}} \mid c_{i}=0\right)=\frac{-\phi\left(x_{o b s, i, t}^{T} \beta+\lambda_{t}\right)}{1-\Phi\left(x_{o b s, i, t}^{T} \beta+\lambda_{t}\right)}$. Let $\phi$ and $\Phi$ denote, respectively, the density function and the cumulative distribution function of $N(0,1)$, we then define a test statistic given by

$$
\begin{gathered}
\widehat{\rho}=\frac{\frac{1}{n} \sum_{i=1}^{n} \widehat{\varepsilon_{i}} \widehat{\eta}_{i}}{\sqrt{\frac{1}{n} \sum_{i=1}^{n} \widehat{\varepsilon_{i}^{2}}} \sqrt{\frac{1}{n} \sum_{i=1}^{n} \widehat{\eta_{i}^{2}}}} \stackrel{d}{\approx} N\left(\rho, \frac{1}{n}\right), \\
n(\widehat{\rho}-\rho)^{2} \stackrel{d}{\approx} \chi^{2}(1),
\end{gathered}
$$

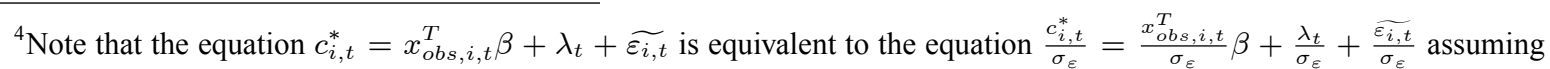
that $\operatorname{var}\left(\widetilde{\varepsilon_{i, t}}\right)=\sigma_{\varepsilon}^{2}$. The conditional correlation coefficent between $\left(c_{i, t}, p_{i, t}\right)$ depends only on the sign of $\left(c_{i, t}^{*}, p_{i, t}^{*}\right)$ not on their absolute scale.
} 
Under the null of $i . i . d$. of the generalized residuals, $\sqrt{n}(\widehat{\rho}-\rho)$ is distributed asymptotically as a standard normal distribution. Consequently, $n(\widehat{\rho}-\rho)^{2}$ is distributed asymptotically as a chisquared $\left(\chi^{2}\right)$ distribution with one degree of freedom. Compared with the test statistic $\Psi$ developed by Gouriéroux, Monfort, Renault, and Trognon's (1987) and employed by Chiappori and Salanie (2000) for testing asymmetric information in the French automobile insurance market,

$$
\Psi=\frac{\left(\sum_{i=1}^{n} \widehat{\varepsilon_{i}} \widehat{\eta}_{i}\right)^{2}}{\sum_{i=1}^{n} \widehat{\varepsilon_{i}^{2}} \widehat{\eta_{i}^{2}}} \stackrel{d}{\approx} \chi^{2}(1)
$$

there are two important advantages of adopting $\widehat{\rho}$ instead of $\Psi$. First, in addition to the common assumption that observations are cross-sectional independently and identically distributed (i.e., i.i.d.), their test statistic is only valid under one more assumption: the pair of generalized residuals are conditional independent, i.e., $\operatorname{Cov}\left(\widehat{\varepsilon_{i}}, \widehat{\eta}_{i}\right)=0$. Second, $\Psi$ fails to retain information on both the direction and the magnitude of correlation. Since the key objective of this paper is to detect the information content of equity-selling mechanisms based on the direction and the magnitude of the conditional association between private placements and insider trading, we adopt $\widehat{\rho}$ as a test statistic instead of $\Psi$.

\subsubsection{The bivariate probit models}

The bivariate probit model explicitly accounts for the cross-equation impact. As a result, it may yield estimators that are asymptotically more efficient than the single-equation approach, provided that the residuals from the two equations are correlated (Zellner and Lee, 1965).

$$
\begin{aligned}
& p_{i, t}^{*}=x_{o b s, i, t}^{T} \gamma+\lambda_{t}+\widetilde{\eta_{i, t}} \\
& c_{i, t}^{*}=x_{o b s, i, t}^{T} \beta+\lambda_{t}+\widetilde{\varepsilon_{i, t}}
\end{aligned}
$$

where $p_{i, t}$ is a binary variable that equals one if three or more insider purchases (sales) and zero insider sales (purchases) occur in the prior 1, 3, 6, or 12 months of the equity offering announcement and zero otherwise, $c_{i, t}$ equals one or zero, depending on whether the firms choose private or public offerings, and $\left(\begin{array}{c}\widetilde{\eta_{i, t}} \\ \widetilde{\varepsilon_{i, t}}\end{array}\right) \stackrel{\text { i.i.d }}{\sim} N\left(0, \sum\right)$, with $\sum=\left(\begin{array}{cc}1 & \rho^{*} \\ \rho^{*} & 1\end{array}\right)$. 
Then $\operatorname{Corr}\left(\widetilde{\eta_{i, t}}, \widetilde{\varepsilon_{i, t}}\right)=\rho^{*}$. Let $\Phi$ denote the cumulative distribution function of $N(0,1)$ and set

$$
F\left(x_{o b s, i, t}^{T} \gamma+\lambda_{t}, x_{o b s, i, t}^{T} \beta+\lambda_{t}, \rho^{*}\right) \equiv \int_{-x_{o b s, i, t}^{T} \beta-\lambda_{t}-x_{o b s, i, t}^{T} \gamma-\lambda_{t}}^{\infty} \frac{e^{-\left[\left(\widetilde{\varepsilon_{i, t}}\right)^{2}+\left(\widetilde{\eta_{i, t}}\right)^{2}-2 \rho^{*} \widetilde{\varepsilon_{i, t}} \widetilde{\eta_{i, t}} /\left[2\left(1-\rho^{* 2}\right)\right]\right]}}{2 \pi \sqrt{1-\rho^{* 2}}} d \widetilde{\eta_{i, t}} d \widetilde{\varepsilon_{i, t}} .
$$

Then

$$
\begin{aligned}
& p\left(p_{i, t}=1\right)=p\left(p_{i, t}^{*}>0\right)=p\left(\widetilde{\eta_{i, t}}<x_{o b s, i, t}^{T} \gamma+\lambda_{t}\right)=\Phi\left(x_{o b s, i, t}^{T} \gamma+\lambda_{t}\right), \\
& p\left(c_{i, t}=1\right)=p\left(c_{i, t}^{*}>0\right)=p\left(-\widetilde{\varepsilon_{i, t}}<x_{o b s, i, t}^{T} \beta+\lambda_{t}\right)=\Phi\left(x_{o b s, i, t}^{T} \beta+\lambda_{t}\right), \\
& p\left(p_{i, t}=1, c_{i, t}=1\right)=p\left(p_{i, t}^{*}>0, c_{i, t}^{*}>0\right)=F\left(x_{o b s, i, t}^{T} \gamma+\lambda_{t}, x_{o b s, i, t}^{T} \beta+\lambda_{t}, \rho^{*}\right), \\
& p\left(c_{i, t}=1, p_{i, t}=0\right)=p\left(c_{i, t}=1\right)-p\left(c_{i, t}=1, p_{i, t}=1\right)=\Phi\left(x_{o b s, i, t}^{T} \beta+\lambda_{t}\right)-F\left(x_{o b s, i, t}^{T} \gamma+\lambda_{t}, x_{o b s, i, t}^{T} \beta+\lambda_{t}, \rho^{*}\right), \\
& p\left(c_{i, t}=0, p_{i, t}=1\right)=p\left(p_{i, t}=1\right)-p\left(c_{i, t}=1, p_{i, t}=1\right)=\Phi\left(x_{o b s, i, t}^{T} \gamma+\lambda_{t}\right)-F\left(x_{o b s, i, t}^{T} \gamma+\lambda_{t}, x_{o b s, i, t}^{T} \beta+\lambda_{t}, \rho^{*}\right), \\
& p\left(c_{i, t}=0, p_{i, t}=0\right)=1-\Phi\left(x_{o b s, i, t}^{T} \beta+\lambda_{t}\right)-\Phi\left(x_{o b s, i, t}^{T} \gamma+\lambda_{t}\right)+F\left(x_{o b s, i, t}^{T} \gamma+\lambda_{t}, x_{o b s, i, t}^{T} \beta+\lambda_{t}, \rho^{*}\right) .
\end{aligned}
$$

The log-likelihood function for the parameters $\theta \equiv\left(\beta^{T}, \gamma^{T}, \rho^{*}\right)^{T}$, is then given by

$$
\begin{aligned}
l(\theta) & =\sum_{i=1}^{n} c_{i, t} p_{i, t} \log \left[F\left(x_{o b s, i, t}^{T} \gamma+\lambda_{t}, x_{o b s, i, t}^{T} \beta+\lambda_{t}, \rho^{*}\right)\right]+ \\
& c_{i, t}\left(1-p_{i, t}\right) \log \left[\Phi\left(x_{o b s, i, t}^{T} \beta+\lambda_{t}\right)-F\left(x_{o b s, i, t}^{T} \gamma+\lambda_{t}, x_{o b s, i, t}^{T} \beta+\lambda_{t}, \rho^{*}\right)\right]+ \\
& p_{i, t}\left(1-c_{i, t}\right) \log \left[\Phi\left(x_{o b s, i, t}^{T} \gamma+\lambda_{t}\right)-F\left(x_{o b s, i, t}^{T} \gamma+\lambda_{t}, x_{o b s, i, t}^{T} \beta+\lambda_{t}, \rho^{*}\right)\right]+ \\
& \left(1-p_{i, t}\right)\left(1-c_{i, t}\right) \log \left[1-\Phi\left(x_{o b s, i, t}^{T} \beta+\lambda_{t}\right)-\Phi\left(x_{o b s, i, t}^{T} \gamma+\lambda_{t}\right)+F\left(x_{o b s, i, t}^{T} \gamma+\lambda_{t}, x_{o b s, i, t}^{T} \beta+\lambda_{t}, \rho^{*}\right)\right]
\end{aligned}
$$

\subsubsection{The mixed binary and censored probit models}

A continuous response variable may better differentiate between varying levels of insiders' perceptions of their firms' prospects, compared to a binary response variable.

$$
\begin{aligned}
& p_{i, t}^{*}=x_{o b s, i, t}^{T} \gamma+\lambda_{t}+\widetilde{\eta_{i, t}}, \\
& c_{i, t}^{*}=x_{o b s, i, t}^{T} \beta+\lambda_{t}+\widetilde{\varepsilon_{i, t}},
\end{aligned}
$$

Let $p_{i, t}=p_{i, t}^{*}$, the number of insider purchases, if the one, three, six, or twelve months prior to the equity offering is an intensive insider purchase event and $p_{i, t}=0$ otherwise, $c_{i, t}=1$ if firm $i$ chooses private placements and $c_{i, t}=0$ if firm $i$ chooses public offerings, and $\left(\begin{array}{c}\widetilde{\eta_{i, t}} \\ \widetilde{\varepsilon_{i, t}}\end{array}\right) \stackrel{i i d}{\sim} N\left(0, \sum\right)$, with 
$\sum=\left(\begin{array}{cc}\sigma^{2} & \rho \sigma \\ \rho \sigma & 1\end{array}\right) 5$.

Let $\phi$ and $\Phi$ denote, respectively, the density function and the cumulative distribution function of $N(0,1)$. The joint density function of $c_{i, t}^{*}$ and $p_{i, t}^{*}$ equals the conditional distribution of $c_{i, t}^{*}$ given $p_{i, t}^{*}$ multiplies the marginal density function of $p_{i, t}^{*}$. The conditional distribution of $c_{i, t}^{*}$ given $p_{i, t}^{*}$ is $N\left(x_{o b s}^{T} \beta+\lambda_{t}+\rho \widetilde{\eta}_{i} / \sigma, 1-\rho^{2}\right)$. Then

$$
\begin{aligned}
p_{c_{i, t}, p_{i, t}^{*}}\left(1, p_{i, t}^{*}\right) & =p\left(c_{i, t}^{*}>0 \mid p_{i, t}^{*}\right) p\left(p_{i, t}^{*}\right)=p\left(c_{i, t}=1 \mid p_{i, t}^{*}\right) p\left(p_{i, t}^{*}\right), \\
& =\frac{1}{\sqrt{2 \pi} \sigma} \Phi\left(\frac{x_{o b s}^{T} \beta+\lambda_{t}+\rho\left(p_{i, t}^{*}-x_{o b s}^{T}-\lambda_{t}\right) / \sigma}{\sqrt{1-\rho^{2}}}\right) \exp \left[\frac{-\left(p_{i, t}^{*}-x_{o b s}^{T} \gamma-\lambda_{t}\right)^{2}}{2 \sigma^{2}}\right]
\end{aligned}
$$

$$
\begin{aligned}
p_{c_{i, t}, p_{i, t}^{*}}\left(0, p_{i, t}^{*}\right) & =p\left(c_{i, t}^{*}<0 \mid p_{i, t}^{*}\right) p\left(p_{i, t}^{*}\right)=p\left(c_{i, t}=0 \mid p_{i, t}^{*}\right) p\left(p_{i, t}^{*}\right) \\
& =\frac{1}{\sqrt{2 \pi} \sigma}\left[1-\Phi\left(\frac{x_{o b s}^{T} \beta+\lambda_{t}+\rho\left(p_{i, t}^{*}-x_{o b s}^{T}-\lambda_{t}\right) / \sigma}{\sqrt{1-\rho^{2}}}\right)\right] \exp \left[\frac{-\left(p_{i, t}^{*}-x_{o b s}^{T} \gamma-\lambda_{t}\right)^{2}}{2 \sigma^{2}}\right]
\end{aligned}
$$

Set parameters

$$
\begin{aligned}
\theta & \equiv\left(\beta^{T}, \gamma^{T}, \sigma^{2}, \rho\right)^{T}, \text { and } \\
g\left(p_{i}^{*}, x_{o b s}, \theta\right) & \equiv\left[x_{o b s}^{T} \beta+\lambda_{t}+\rho\left(p_{i, t}^{*}-x_{o b s}^{T}-\lambda_{t}\right) / \sigma\right] / \sqrt{1-\rho^{2}} .
\end{aligned}
$$

Then the log-likelihood function for the parameters $\theta$ is

$$
l(\theta)=\sum_{i=1}^{n}-\frac{1}{2} \log \left(2 \pi \sigma^{2}\right)-\frac{\left(p_{i, t}^{*}-x_{o b s}^{T} \gamma-\lambda_{t}\right)^{2}}{2 \sigma^{2}}+c_{i} \log \left[\Phi\left(g\left(p_{i}^{*}, x_{o b s}, \theta\right)\right)\right]+\left(1-c_{i}\right) \log \left[1-\Phi\left(g\left(p_{i}^{*}, x_{o b s}, \theta\right)\right)\right] .
$$

We estimate $\theta$ by solving the likelihood equation(or score equation) $\partial l(\theta) /\left.\partial \theta\right|_{\theta=\widehat{\theta}}=0$, where

$$
\begin{aligned}
\frac{\partial l(\theta)}{\partial \beta} & =\sum_{i=1}^{n} \frac{\phi\left(g\left(p_{i}^{*}, x_{o b s}, \theta\right)\right)}{\sqrt{1-\rho^{2}}}\left[\frac{c_{i}}{\Phi\left(g\left(p_{i}^{*}, x_{o b s}, \theta\right)\right)}-\frac{1-c_{i}}{1-\Phi\left(g\left(p_{i}^{*}, x_{o b s}, \theta\right)\right)}\right] x_{o b s}, \\
\frac{\partial l(\theta)}{\partial \gamma} & =\sum_{i=1}^{n}\left\{\frac{p_{i}^{*}-x_{o b s}^{T} \gamma}{\sigma^{2}}-\frac{\rho \phi\left(g\left(p_{i}^{*}, x_{o b s}, \theta\right)\right)}{\sqrt{1-\rho^{2}} \sigma}\left[\frac{c_{i}}{\Phi\left(g\left(p_{i}^{*}, x_{o b s}, \theta\right)\right)}-\frac{1-c_{i}}{1-\Phi\left(g\left(p_{i}^{*}, x_{o b s}, \theta\right)\right)}\right]\right\} x_{o b s}, \\
\frac{\partial l(\theta)}{\partial \sigma^{2}} & =\sum_{i=1}^{n}-\frac{1}{2 \sigma^{2}}+\frac{\left(p_{i}^{*}-x_{o b s}^{T} \gamma\right)^{2}}{2 \sigma^{4}}-\frac{\rho \phi\left(g\left(p_{i}^{*}, x_{o b s}, \theta\right)\right)\left(p_{i}^{*}-x_{o b s}^{T} \gamma\right)}{2 \sqrt{1-\rho^{2}} \sigma^{3}}\left[\frac{c_{i}}{\Phi\left(g\left(p_{i}^{*}, x_{o b s}, \theta\right)\right)}-\frac{1-c_{i}}{1-\Phi\left(g\left(p_{i}^{*}, x_{o b s}, \theta\right)\right)}\right], \\
\frac{\partial l(\theta)}{\partial \rho} & =\sum_{i=1}^{n} \frac{\phi\left(g\left(p_{i}^{*}, x_{o b s}, \theta\right)\right)\left[\left(1-\rho^{2}\right)\left(p_{i}^{*}-x_{o b s}^{T} \gamma\right)+\rho \sigma g\left(p_{i}^{*}, x_{o b s}, \theta\right)\right]}{\left(1-\rho^{2}\right)^{3 / 2} \sigma}\left[\frac{c_{i}}{\Phi\left(g\left(p_{i}^{*}, x_{o b s}, \theta\right)\right)}-\frac{1-c_{i}}{1-\Phi\left(g\left(p_{i}^{*}, x_{o b s}, \theta\right)\right)}\right] .
\end{aligned}
$$

\footnotetext{
${ }^{5}$ To save space in the derivation, we consider $x_{o b s}$ only by ignoring the firm $i$ and the time $t$ notation.
} 
The observed Fisher information for $\theta$ is $-\partial^{2} l(\theta) /\left.\partial \theta \partial \theta^{T}\right|_{\theta=\widehat{\theta}}$, where

$$
\begin{aligned}
& \frac{\partial^{2} l(\theta)}{\partial \beta \partial \beta^{T}}=\sum_{i=1}^{n}-\frac{1}{1-\rho^{2}}\left\{\begin{array}{c}
{\left[\phi\left(g\left(p_{i}^{*}, x_{o b s}, \theta\right)\right)\right]^{2}\left\{\frac{c_{i}}{\left[\Phi\left(g\left(p_{i}^{*}, x_{o b s}, \theta\right)\right)\right]^{2}}+\frac{1-c_{i}}{\left[1-\Phi\left(g\left(p_{i}^{*}, x_{o b s}, \theta\right)\right)\right]^{2}}\right\}} \\
-\phi^{\prime}\left(g\left(p_{i}^{*}, x_{o b s}, \theta\right)\right)\left[\frac{c_{i}}{\Phi\left(g\left(p_{i}^{*}, x_{o b s}, \theta\right)\right)}-\frac{1-c_{i}}{1-\Phi\left(g\left(p_{i}^{*}, x_{o b s}, \theta\right)\right)}\right]
\end{array}\right\} x_{o b s} x_{o b s}^{T}, \\
& \frac{\partial^{2} l(\theta)}{\partial \beta \partial \gamma^{T}}=\sum_{i=1}^{n}-\frac{\rho}{\sigma\left(1-\rho^{2}\right)}\left\{\begin{array}{c}
{\left[\phi\left(g\left(p_{i}^{*}, x_{o b s}, \theta\right)\right)\right]^{2}\left\{\frac{c_{i}}{\left[\Phi\left(g\left(p_{i}^{*}, x_{o b s}, \theta\right)\right)\right]^{2}}+\frac{1-c_{i}}{\left[1-\Phi\left(g\left(p_{i}^{*}, x_{o b s}, \theta\right)\right)\right]^{2}}\right\}} \\
-\phi^{\prime}\left(g\left(p_{i}^{*}, x_{o b s}, \theta\right)\right)\left[\frac{c_{i}}{\Phi\left(g\left(p_{i}^{*}, x_{o b s}, \theta\right)\right)}-\frac{1-c_{i}}{1-\Phi\left(g\left(p_{i}^{*}, x_{o b s}, \theta\right)\right)}\right]
\end{array}\right\} x_{o b s} x_{o b s}^{T}, \\
& \frac{\partial^{2} l(\theta)}{\partial \beta \partial \sigma^{2}}=\sum_{i=1}^{n} \frac{\rho\left(p_{i}^{*}-x_{o b s}^{T} \gamma\right)}{2 \sigma^{3}\left(1-\rho^{2}\right)}\left\{\begin{array}{c}
{\left[\phi\left(g\left(p_{i}^{*}, x_{o b s}, \theta\right)\right)\right]^{2}\left\{\frac{c_{i}}{\left[\Phi\left(g\left(p_{i}^{*}, x_{o b s}, \theta\right)\right)\right]^{2}}+\frac{1-c_{i}}{\left[1-\Phi\left(g\left(p_{i}^{*}, x_{o b s}, \theta\right)\right)\right]^{2}}\right\}} \\
-\phi^{\prime}\left(g\left(p_{i}^{*}, x_{o b s}, \theta\right)\right)\left[\frac{c_{i}}{\Phi\left(g\left(p_{i}^{*}, x_{o b s}, \theta\right)\right)}-\frac{1-c_{i}}{1-\Phi\left(g\left(p_{i}^{*}, x_{o b s}, \theta\right)\right)}\right]
\end{array}\right\} x_{o b s}, \\
& \frac{\partial^{2} l(\theta)}{\partial \beta \partial \rho}=\sum_{i=1}^{n}-\frac{\left(1-\rho^{2}\right)\left(p_{i}^{*}-x_{o b s}^{T} \gamma\right)+\rho \sigma g\left(p_{i}^{*}, x_{o b s}, \theta\right)}{\sigma\left(1-\rho^{2}\right)^{2}} \\
& \left\{\begin{array}{c}
{\left[\phi\left(g\left(p_{i}^{*}, x_{o b s}, \theta\right)\right)\right]^{2}\left\{\frac{c_{i}}{\left[\Phi\left(g\left(p_{i}^{*}, x_{o b s}, \theta\right)\right)\right]^{2}}+\frac{1-c_{i}}{\left[1-\Phi\left(g\left(p_{i}^{*}, x_{o b s}, \theta\right)\right)\right]^{2}}\right\}} \\
-\phi^{\prime}\left(g\left(p_{i}^{*}, x_{o b s}, \theta\right)\right)\left[\frac{c_{i}}{\Phi\left(g\left(p_{i}^{*}, x_{o b s}, \theta\right)\right)}-\frac{1-c_{i}}{1-\Phi\left(g\left(p_{i}^{*}, x_{o b s}, \theta\right)\right)}\right] \\
+\frac{\rho \phi\left(g\left(p_{i}^{*}, x_{o b s}, \theta\right)\right)}{\left(1-\rho^{2}\right)^{3 / 2}}\left[\frac{c_{i}}{\Phi\left(g\left(p_{i}^{*}, x_{o b s}, \theta\right)\right)}-\frac{1-c_{i}}{1-\Phi\left(g\left(p_{i}^{*}, x_{o b s}, \theta\right)\right)}\right]
\end{array}\right\} x_{o b s}, \\
& \frac{\partial^{2} l(\theta)}{\partial \gamma \partial \beta^{T}}=\left[\frac{\partial^{2} l(\theta)}{\partial \beta \partial \gamma^{T}}\right]^{T}
\end{aligned}
$$$$
\begin{aligned}
& \frac{\partial^{2} l(\theta)}{\partial \gamma \partial \gamma^{T}}=\sum_{i=1}^{n}-\frac{1}{\sigma^{2}} \\
& \left\{\begin{array}{c}
\left.1-\frac{\rho^{2}}{\left(1-\rho^{2}\right)}\left\{\begin{array}{c}
{\left[\phi\left(g\left(p_{i}^{*}, x_{o b s}, \theta\right)\right)\right]^{2}\left\{\frac{c_{i}}{\left[\Phi\left(g\left(p_{i}^{*}, x_{o b s}, \theta\right)\right)\right]^{2}}+\frac{1-c_{i}}{\left[1-\Phi\left(g\left(p_{i}^{*}, x_{o b s}, \theta\right)\right)\right]^{2}}\right\}} \\
+\phi^{\prime}\left(g\left(p_{i}^{*}, x_{o b s}, \theta\right)\right)\left[\frac{c_{i}}{\Phi\left(g\left(p_{i}^{*}, x_{o b s}, \theta\right)\right)}-\frac{1-c_{i}}{1-\Phi\left(g\left(p_{i}^{*}, x_{o b s}, \theta\right)\right)}\right]
\end{array}\right\}\right\} x_{o b s} x_{o b s}^{T},
\end{array}\right.
\end{aligned}
$$$$
\frac{\partial^{2} l(\theta)}{\partial \gamma \partial \sigma^{2}}=\sum_{i=1}^{n}\left\{-\frac{p_{i}^{*}-x_{o b s}^{T} \gamma}{\sigma^{4}}+\frac{1}{\sigma^{3}}\left\{\begin{array}{c}
\frac{\rho \phi\left(g\left(p_{i}^{*}, x_{o b s}, \theta\right)\right)}{\sqrt{1-\rho^{2}}}\left[\frac{c_{i}}{\Phi\left(g\left(p_{i}^{*}, x_{o b s}, \theta\right)\right)}-\frac{1-c_{i}}{1-\Phi\left(g\left(p_{i}^{*}, x_{o b s}, \theta\right)\right)}\right] \\
+\frac{\rho^{2}\left(p_{i}^{*}-x_{o b s}^{T} \gamma\right)}{2 \sigma\left(1-\rho^{2}\right)}\left[\phi\left(g\left(p_{i}^{*}, x_{o b s}, \theta\right)\right)\right]^{2} \\
\left\{\frac{c_{i}}{\left[\Phi\left(g\left(p_{i}^{*}, x_{o b s}, \theta\right)\right)\right]^{2}}+\frac{1-c_{i}}{\left[1-\Phi\left(g\left(p_{i}^{*}, x_{o b s}, \theta\right)\right)\right]^{2}}\right\} \\
-\frac{\rho^{2}\left(p_{i}^{*}-x_{o b s}^{T} \gamma\right)}{2 \sigma\left(1-\rho^{2}\right)} \phi^{\prime}\left(g\left(p_{i}^{*}, x_{o b s}, \theta\right)\right) \\
{\left[\frac{c_{i}}{\Phi\left(g\left(p_{i}^{*}, x_{o b s}, \theta\right)\right)}-\frac{1-c_{i}}{1-\Phi\left(g\left(p_{i}^{*}, x_{o b s}, \theta\right)\right)}\right]}
\end{array}\right\} x_{o b s,}\right.
$$

$$
\begin{aligned}
& \frac{\partial^{2} l(\theta)}{\partial \gamma \partial \rho}=\sum_{i=1}^{n} \frac{\rho \phi\left(g\left(p_{i}^{*}, x_{o b s}, \theta\right)\right)\left[\left(1-\rho^{2}\right)\left(p_{i}^{*}-x_{o b s}^{T} \gamma\right)+\rho \sigma g\left(p_{i}^{*}, x_{o b s}, \theta\right)\right]}{\sigma^{2}\left(1-\rho^{2}\right)^{2}} \\
& \left\{\begin{array}{c}
{\left[\phi\left(g\left(p_{i}^{*}, x_{o b s}, \theta\right)\right)\right]^{2}\left\{\frac{c_{i}}{\left[\Phi\left(g\left(p_{i}^{*}, x_{o b s}, \theta\right)\right)\right]^{2}}+\frac{1-c_{i}}{\left[1-\Phi\left(g\left(p_{i}^{*}, x_{o b s}, \theta\right)\right)\right]^{2}}\right\}-} \\
\phi^{\prime}\left(g\left(p_{i}^{*}, x_{o b s}, \theta\right)\right)\left[\frac{c_{i}}{\Phi\left(g\left(p_{i}^{*}, x_{o b s}, \theta\right)\right)}-\frac{1-c_{i}}{1-\Phi\left(g\left(p_{i}^{*}, x_{o b s}, \theta\right)\right)}\right]- \\
\frac{\phi\left(g\left(p_{i}^{*}, x_{o b s}, \theta\right)\right)}{\left(1-\rho^{2}\right)^{3 / 2} \sigma}\left[\frac{c_{i}}{\Phi\left(g\left(p_{i}^{*}, x_{o b s}, \theta\right)\right)}-\frac{1-c_{i}}{\left.1-\overline{4}^{\Phi\left(g\left(p_{i}^{*}, x_{o b s}, \theta\right)\right)}\right]}\right\}
\end{array}\right\} x_{o b s,},
\end{aligned}
$$




$$
\begin{aligned}
& \frac{\partial^{2} l(\theta)}{\partial \sigma^{2} \partial \beta^{T}}=\left[\frac{\partial^{2} l(\theta)}{\partial \beta \partial \sigma^{2}}\right]^{T} \\
& \frac{\partial^{2} l(\theta)}{\partial \sigma^{2} \partial \gamma^{T}}=\left[\frac{\partial^{2} l(\theta)}{\partial \gamma \partial \sigma^{2}}\right]^{T} \\
& \sum_{i=1}^{n} \frac{1}{2 \sigma^{4}}-\frac{\left(p_{i}^{*}-x_{o b s}^{T} \gamma\right)^{2}}{\sigma^{6}}+\frac{\rho \phi\left(g\left(p_{i}^{*}, x_{o b s}, \theta\right)\right)\left(p_{i}^{*}-x_{o b s}^{T} \gamma\right)}{4 \sqrt{1-\rho^{2}} \sigma^{4}}\left[\frac{c_{i}}{\Phi\left(g\left(p_{i}^{*}, x_{o b s}, \theta\right)\right)}-\frac{1-c_{i}}{1-\Phi\left(g\left(p_{i}^{*}, x_{o b s}, \theta\right)\right)}\right] \\
& \frac{\partial^{2} l(\theta)}{\partial \sigma^{2} \partial \sigma^{2}}=-\frac{\rho^{2}\left(p_{i}^{*}-x_{o b s}^{T} \gamma\right)^{2}}{4\left(1-\rho^{2}\right) \sigma^{6}}\left\{\begin{array}{c}
{\left[\phi\left(g\left(p_{i}^{*}, x_{o b s}, \theta\right)\right)\right]^{2}} \\
\left\{\frac{c_{i}}{\left[\Phi\left(g\left(p_{i}^{*}, x_{o b s}, \theta\right)\right)\right]^{2}}+\frac{1-c_{i}}{\left[1-\Phi\left(g\left(p_{i}^{*}, x_{o b s}, \theta\right)\right)\right]^{2}}\right\} \\
-\phi^{\prime}\left(g\left(p_{i}^{*}, x_{o b s}, \theta\right)\right)\left[\frac{c_{i}}{\Phi\left(g\left(p_{i}^{*}, x_{o b s}, \theta\right)\right)}-\frac{1-c_{i}}{1-\Phi\left(g\left(p_{i}^{*}, x_{o b s}, \theta\right)\right)}\right]
\end{array}\right\} \\
& \sum_{i=1}^{n}-\frac{\left(p_{i}^{*}-x_{o b s}^{T} \gamma\right)}{2\left(1-\rho^{2}\right)^{3 / 2} \sigma^{3}} \phi\left(g\left(p_{i}^{*}, x_{o b s}, \theta\right)\right)\left[\frac{c_{i}}{\Phi\left(g\left(p_{i}^{*}, x_{o b s}, \theta\right)\right)}-\frac{1-c_{i}}{1-\Phi\left(g\left(p_{i}^{*}, x_{o b s}, \theta\right)\right)}\right]
\end{aligned}
$$

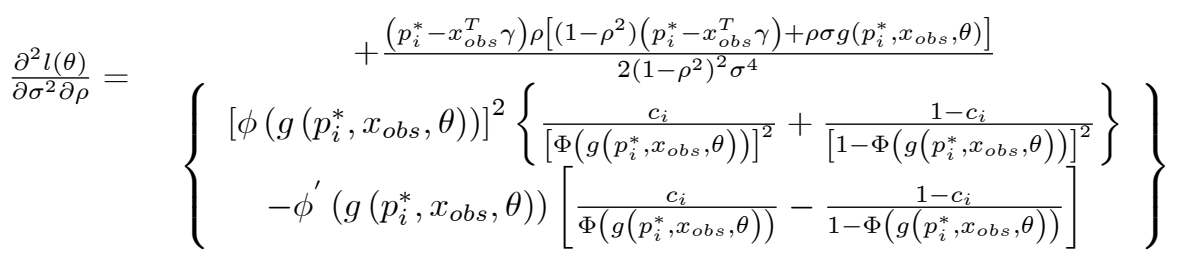

$$
\begin{aligned}
& \frac{\partial^{2} l(\theta)}{\partial \rho \partial \beta^{T}}=\left[\frac{\partial^{2} l(\theta)}{\partial \beta \partial \rho}\right]^{T} \\
& \frac{\partial^{2} l(\theta)}{\partial \rho \partial \gamma^{T}}=\left[\frac{\partial^{2} l(\theta)}{\partial \gamma \partial \rho}\right]^{T} \\
& \frac{\partial^{2} l(\theta)}{\partial \rho \partial \sigma^{2}}=\left[\frac{\partial^{2} l(\theta)}{\partial \sigma^{2} \partial \rho}\right]^{T} \\
& \begin{aligned}
& \sum_{i=1}^{n}\left\{\begin{array}{c}
\frac{\rho\left(p_{i}^{*}-x_{o b s}^{T} \gamma\right)}{\left(1-\rho^{2}\right)^{3 / 2} \sigma}+\frac{\left[g\left(p_{i}^{*}, x_{o b s}, \theta\right)\right]^{2}}{\left(1-\rho^{2}\right)^{3 / 2}} \\
\left.-\frac{\rho\left[\left(1-\rho^{2}\right)\left(p_{i}^{*}-x_{o b s}^{T} \gamma\right)+\rho \sigma g\left(p_{i}^{*}, x_{o b s}, \theta\right)\right]}{\left(1-\rho^{2}\right)^{3 / 2} \sigma}\right\}\left[\frac{c_{i}}{\partial \rho \partial \rho}-\frac{1-c_{i}}{1-\Phi\left(g\left(p_{i}^{*}, x_{o b s}, \theta\right)\right)}\right]
\end{array}\right. \\
&\left\{\begin{array}{c}
{\left[\phi\left(g\left(p_{i}^{*}, x_{o b s}, \theta\right)\right)\right.} \\
-\frac{\left[\left(p_{i}^{*}-x_{o b s}^{T} \gamma\right)\left(1-\rho^{2}\right)+\rho \sigma g\left(p_{i}^{*}, x_{o b s}, \theta\right)\right]^{2}}{\left(1-\rho^{2}\right)^{3} \sigma^{2}} \\
\left.-\phi^{\prime}\left(g\left(p_{i}^{*}, x_{o b s}, \theta\right)\right)\right]^{2}\left\{\frac{c_{i}}{\left[\Phi\left(g\left(p_{i}^{*}, x_{o b s}, \theta\right)\right)\right]^{2}}+\frac{1-c_{i}}{\left[1-\Phi\left(g\left(p_{i}^{*}, x_{o b s}, \theta\right)\right)\right]^{2}}\right\}
\end{array}\right\}
\end{aligned}
\end{aligned}
$$

\subsection{The non-parametric approach}

The discussion so far assumes that the error disturbances are normally distributed.and that a parametric function for the conditional expectation of a dependent variable has been specified correctly. 
However, There is no prior assumption that the intrinsic relation between $x_{\text {unobs }, i}$ and $x_{o b s, i}$ must be linear (see Chen, Ho, Lee, and Shrestha (2004) on using residual analysis technique to detect the nonlinear specification in corporate finance research). It is also possible for the pair of informed parties' decisions given observable variables to be linearly uncorrelated but dependent.

Since the functional forms of the parametric procedures are relatively restrictive. we propose a nonparametric approach based on sign test, and a chi-squares test for independence.

\subsubsection{Sign test and Chi-squared test for independence}

A sign tests based on a $2 x 2$ contingency table are performed to examine whether the signs of the generalized residuals for equity-selling mechanism choice $\left(\widehat{\varepsilon_{i}}\right)$ match with the signs of the generalized residuals for insider trades $\left(\widehat{\eta}_{i}\right)$ from equation (5) using the saturated models (models that include a exhaustive set of $x_{o b s, i}$ ) under two independent probit models, the bivariate probit models, and the mixed binary and censored probit models. ${ }^{6}$ Here, we also use the non-parametric Chi-square test to examine if the estimated impact of abnormal insider purchases (sales) is sensitive to the methodological approach The proposed grouping is to let $x_{i}$ be a vector of $m$ (number of independent variables) dummies (either 0 or 1 ). Firms having the same values for $m$ dummies are grouped by $2^{m}$. In each grouping, a two-by-two classification table generated by the values of $c_{i}$ and $p_{i}$ is computed. Let $j=0,1$.

\begin{tabular}{lll}
\hline & $p_{i}=0$ & $p_{i}=1$ \\
\hline$c_{i}=0$ & $n_{00}$ & $n_{01}$ \\
\hline$c_{i}=1$ & $n_{10}$ & $n_{11}$
\end{tabular}

Define $n_{j .}=n_{j 0}+n_{j 1}, n_{. j}=n_{0 j}+n_{1 j}$, and $n_{. .}=n_{.0}+n_{.1}$. Now consider the test statistic $V_{m}=\sum_{j, k=0,1} \frac{\left[n_{j k}-\left(n_{j .} n_{. k} / n_{. .}\right)\right]^{2}}{n_{j k}}$, which is the well-known $\chi^{2}$ test for independence. If $c_{i}$ and $p_{i}$ are independently distributed, then $V_{m}$ is $\chi^{2}(1)$. The probability of rejecting independence in each grouping is assumed to be 0.05 . That is, if the value of $V_{m}$ for a certain grouping is greater than 3.84, the 5 percent critical value for $\chi^{2}(1)$, the null hypothesis of independence is rejected. Furthermore, if $V_{m}$ is assumed to be independent between groupings, then the probability of rejecting independence for the $2^{m}$ groupings has a binomial distribution with the number of trials equals $2^{m}$ and the

\footnotetext{
${ }^{6}$ Bear in mind that the estimated generalized residuals in binary response models $\left(\mathrm{c}_{i}, \mathrm{p}_{i}\right)$ are not direct measures of error terms from the underlying regression models where the dependent variables $\left(c_{i}^{*}, p_{i}^{*}\right)$ are not directly observable.

The estimated correlation coefficient for the individual generalized residuals is as follows:

$\widehat{\rho}=\frac{E\left[\left(c_{i}-E\left(c_{i}\right)\right)\left(p_{i}-E\left(p_{i}\right)\right)\right]}{\sqrt{\operatorname{var}\left(c_{i}-E\left(c_{i}\right)\right)} \sqrt{\operatorname{var}\left(p_{i}-E\left(p_{i}\right)\right)}}=\frac{E\left(c_{i}=1, p_{i}=1\right)-E\left(c_{i}=1\right) E\left(p_{i}=1\right)}{\sqrt{\operatorname{var}\left(c_{i}-E\left(c_{i}\right)\right)} \sqrt{\operatorname{var}\left(p_{i}-E\left(p_{i}\right)\right)}}$. Since $\operatorname{Max}\left(0,1-\Phi\left(x_{o b s, i}^{T} \beta\right)-\Phi\left(x_{o b s, i}^{T} \gamma\right)\right) \leq$ $E\left(c_{i}=1, p_{i}=1\right) \leq \operatorname{Min}\left(\Phi\left(x_{o b s, i}^{T} \beta\right), \Phi\left(x_{o b s, i}^{T} \gamma\right)\right)$.

Therefore, the range of $\widehat{\rho}$ is bounded within certain range and varies with the independent variable. Becasue of this important caveat, we propose to use the sign test that focuses on the sign as a robustness test.
} 
probability of success equals 0.05 , the probability of rejecting independence in each grouping. The statistic is generated by adding up the $V_{m}$ values for $2^{m}$ cells, which is distributed as a $\chi^{2}\left(2^{m}\right)$.

To implement this test, we first need to do the groupings. It is infeasible to use all observable variables $\left(x_{o b s}\right)$, since it will result in too small number of observations in each cell. We could use around four to five variables, depending on the sample size, that are highly significant in the regressions for equity-selling mechanism choices and the intensity of insider trading.

\section{Conclusions}

Recently, there has been a considerable debate on the information content of the equity-selling mechanisms. This paper adopts a two-stage estimation approach and a conditional correlation methodology to re-examine this debate. This paper assumes that both the choice of equity-selling mechanisms and insider trades are driven by the same set of private information. This paper uses the estimated residuals from the insider trading regression as a measure of insiders' superior information about the firm's prospects and hypothesizes that private placement firms are undervalued when the estimated residuals from the insider purchase (sale) regression correlate positively (negatively) with the probability of making private placements. The conditional correlation coefficient we explore is quite different from Pearson correlations in that it is purged of public information and measures correlation between two set of private information. These two approaches help to circumvent the problems with cross-sectional studies that proxies for information asymmetry are plagued by significant measurement errors and the problems with event studies that long-term ex post stock performance may be endogenously affected by equity-selling mechanisms (Wruck (1989)) and statistical significant event date returns could be driven by market microstructure problems (Lease, Masulis, and Page, (1991)) or long-term event-study methodologies (Mitchell and Stafford (2000)).

This conditional correlation is initially used by Chiappori and Salanie (2000). This paper relaxes an extremely restrictive assumption required by Chiappori's and Salanie's test statistic (pp. 66) of conditional independence within residuals of a pair of regressions and retains information on both the direction and magnitude of correlation. This retention is crucial because the key objective of this paper is to detect the direction of the conditional association in order to infer whether private placements signal positive, negative, or no firm-specific private information, respectively. In our application of the conditional correlation approach, one of the pair of the informed parties' decisions is the equity selling mechanism choice and the other informed parties' decision is the insider trading activity. Instead of using the insider trading, we could use the revisions in analysts' EPS forecasts. Studies widely use analysts as a good proxy for well-informed investors (e.g., Womack (1996)). The rationality of analysts' EPS forecasts is supported by Keane and Runkle (1998). The rationality is in the sense of Muth (1961), that is, the analysts' EPS forecasts are equal to the expectation of actual 
EPS, conditional on the available information at forecasting date. This paper applies the conditional correlation approach to incorporate cases where both response variables are binary and cases where response variables are continuous instead of binary. Similar application of the conditional correlation approach in other setting may allow researchers to answer other important empirical questions more convincingly.

Apart from its methodological contribution, the empirical results shed light on the debate over private placement puzzles and the estimates could offer suggestions to the SEC proposal of integrating private and public offerings (Davidson, Nash, and Plumridge, 1998, pp. 151-382).

\section{References}

[1] Barclay, Michael J., Holderness, Clifford G., and Sheehan, Dennis P., 2007. Private placements and managerial entrenchment. Unpublished working paper. Boston College.

[2] Biais, B., and Hillion, P., 1994. Insider and liquidity trading in stock and options markets. Review of Financial Studies 7, 743-780.

[3] Boehmer, E., and Netter, Jeffry M., 1997. Management optimism and corporate acquisitions: Evidence from insider trading. Managerial and Decision Economics 18, 693-708.

[4] Chen, Sheng-Syan, Kim Wai Ho, Cheng-few Lee, and Keshab Shrestha, March 2004, "Nonlinear models in corporate finance research: Review, critique, and extensions," Review of Quantitative Finance and Accounting 22, No. 2, 141-169.

[5] Chiappori, Pierre-A., Salanie B., 2000. Testing for asymmetric information in insurance markets. Journal of Political Economy 108, 56-78.

[6] Clarke, J., Dunbar, C., and Kahle, Kathleen M., 2001. Long-run performance and insider trading in completed and canceled seasoned equity offerings. Journal of Financial and Quantitative Analysis 36, 415-430.

[7] Damodaran, A., and Liu, Crocker, H., 1993. Insider trading as a signal of private information. Review of Financial Studies 6, 79-119.

[8] Davidson Gordon K., Nash Robert C., Plumridge Richard R., 1998. Private placements. Practicing Law Institute, New York.

[9] Goh, J., Gombola, Michael J., Lee, Hei W., and Liu Feng, Y., 1999. Private placement of common equity and earnings expectations. Financial Review 34, 19-32.

[10] Gouriéroux, C., Monfort, A., Renault, E., and Trognon., A., 1987. Generalized residuals. Journal of Econometrics 34, 5-32.

[11] Hertzel, Michael G., Lemmon, M., Linck, J., and Rees, L., 2002. Long-run performance following private placements of equity. Journal 18 f Finance 57, 2595-2617. 
[12] Hertzel, Michael G., and Rees, L., 1998. Earnings and risk changes around private placements of equity. Journal of Accounting, Auditing and Finance13, 21-35.

[13] Hertzel, Michael G., and Smith, Richard L., 1993. Market discounts and shareholder gains for placing equity privately. Journal of Finance 48, 459-485.

[14] Huson Mark R., Malatesta Paul H., and Parrino R., 2006. Capital market conditions and the volume and pricing of private equity sales.Unpublished working paper. University of Alberta, University of Washington and University of Texas at Austin.

[15] Jaffe, Jeffrey F., 1974. Special information and insider trading. Journal of Business 47, 410-428.

[16] Jain, Prem C., 1992. Equity issues and changes in expectations of earnings by financial analysts. Review of Financial Studies 5, 669-683.

[17] John, K., Lang, Larry H. P., 1991. Insider trading around dividend announcements: Theory and evidence. Journal of Finance 46, 1361-1389.

[18] John, K., and Mishra, B., 1990. Information content of insider trading around corporate announcements: The case of capital expenditures. Journal of Finance 45, 835-855.

[19] Kahle, Kathleen M., 2000. Insider trading and the long-run performance of new security issues. Journal of Corporate Finance: Contracting, Governance and Organization 6, 25-53.

[20] Karpoff, Jonathan M., and Lee, D., 1991. Insider trading before new issue announcements. Financial Management 20, 18-26.

[21] Keane, Michael P., Runkle David E., 1998. Are financial analysts' forecasts of corporate profits rational? Journal of Political Economy 106, 768-805.

[22] Keown, Arthur J., and Pinkerton, John M., 1981. Merger announcements and insider trading activity: An empirical investigation. Journal of Finance 36, 855-869.

[23] Krishnamurthy S., Paul, S., Venkat, S., and Tracie, W., 2005. Does equity placement type matter? Evidence from long-term stock performance following private placements. Journal of Financial Intermediation 14, 210-238.

[24] Lakonishok, J., and Lee, I., 2001. Are insider trades informative? Review of Financial Studies $14,79-111$.

[25] Lease, Ronald C., Masulis, Ronald W. and Page, J. 1991. An investigation of market microstructure impacts on event study returns. Journal of Finance 46, 1523-1536.

[26] Lee, I., 1997. Do firms knowingly sell overvalued equity? Journal of Finance 52, 1439-1466.

[27] Lee Cheng-Few and Wu YiLin., 2007. An econometric investigation of the information content of equity-selling mechanisms. Forthcoming in Review of Quantitative Finance and Accounting.

[28] Lin, Ji C., and Howe, John S., 1990. Insider trading in the OTC market. Journal of Finance 45, $1273-1284$ 
[29] Loughran, T., and Ritter, Jay R., 1995. The new issues puzzle. Journal of Finance 50, 23-51.

[30] Loughran, T., and Ritter, Jay R., 1997. The operating performance of firms conducting seasoned equity offerings. Journal of Finance 52, 1823-1850.

[31] Masulis, R. W., and Korwar, A. N., 1986. Seasoned equity offerings: An empirical investigation. Journal of Financial Economics 15, 91-118.

[32] Meulbroek, Lisa A., 1992. An empirical analysis of illegal insider trading. Journal of Finance 47, 1661-1699.

[33] Mitchell, Mark L., Stafford, E., 2000. Managerial decisions and long-term stock price performance. Journal of Business 73, 287-329.

[34] Muth, J.F., 1961. Rational expectations and the theory of price movements, Econometrica 29, $315-335$.

[35] Myers, Stewart C., and Majluf, Nicholas S.,1984. Corporate financing and investment decisions when firms have information that investors do not have. Journal of Financial Economics13, 187-221.

[36] Park, S., Jang, H J., and Loeb, Martin P., 1995. Insider trading activity surrounding annual earnings announcements. Journal of Business Finance \& Accounting 22, 587-614.

[37] Piotroski Joseph D., Roulstone D., 2005. Do insider trades reflect both contrarian beliefs and superior knowledge about future cash flow realizations? Journal of Accounting and Economics $39,55-82$.

[38] Rozeff, Michael S., and Zaman, Mir A., 1988. Market efficiency and insider trading: New evidence. Journal of Business 61, 25-44.

[39] Rozeff, Michael S., and Zaman, Mir A., 1998. Overreaction and insider trading: Evidence from growth and value Portfolios. Journal of Finance 53, 701-716.

[40] Seyhun, H. N., 1986. Insiders' profits, costs of trading, and market efficiency. Journal of Financial Economics 16, 189-212.

[41] Seyhun, H. N., 1992. Why does aggregate insider trading predict future stock returns? Quarterly Journal of Economics 107, 1303-1331.

[42] Womack,K. 1996. Do brokerage analysts' recommendations have investment value? Journal of Finance 51, 137-167.

[43] Wruck, H. K., 1989. Equity ownership concentration and firm value: Evidence from private equity financings. Journal of Financial Economics 23, 3-28.

[44] Wu YiLin., 2004. The choice of equity-selling mechanisms. Journal of Financial Economics 74, 93-119. 